'What happens when you intuit?' Understanding human resource practitioners' subjective experience of intuition through a novel linguistic method

Eugene Sadler-Smith

Address for correspondence

Eugene Sadler-Smith

Surrey Business School

University of Surrey

Guildford, GU2 7XH

UNITED KINGDOM

Email: e.sadler-smith@surrey.ac.uk 


\title{
'What happens when you intuit?' Understanding human resource practitioners' subjective experience of intuition through a novel linguistic method
}

\begin{abstract}
The objective of this research was to understand the phenomenon of intuition from the perspective of the intuitor. Against a background of a steadily growing interest in intuition in managerial decision research, and inclining towards a phenomenological stance, the research used a novel linguistic method based on 'de-nominalization' to access participants' (124 human resource practitioners) experiences of intuition. Based on an analysis of responses to the question 'what happens when you intuit?' the article: defines intuition based on participants' subjective experiences; reveals the subjective experience of intuition as comprising three phases - 'intuiting', 'intuition', and 'implementing'; uncovers two aspects of intuitive affect - 'bodily awareness' and 'cognitive awareness'; establishes that participants use primary metaphors to articulate their experiences of intuition. The article outlines the theoretical implications and practical relevance of these findings, and makes suggestions for further qualitative phenomenological studies of intuition.
\end{abstract}

\section{Keywords}

Decision making; intuition; human resources; linguistic method; nominalization; phenomenology; subjective experience 


\section{Introduction}

The motivation for this research is a keen interest in the subjective experience of intuition. For many decades the study of intuition inhabited the fringes of social science, it was often equated with "parapsychology, telepathy, and premonition...esoteric and 'New Age' thinking” (Hodgkinson, Langan-Fox \& Sadler-Smith, 2008: 1). Recent years have witnessed a surge of interest in intuition amongst organizational researchers (Akinci \& Sadler-Smith, 2012; Sinclair, 2011, 2014). Consequently there have been many important advances in defining, conceptualizing, and theorizing the construct (e.g. Dane \& Pratt, 2007; Dörfler \& Akermann, 2013; Hodgkinson \& Clarke, 2007; Hogarth, 2010; Salas, Rosen \& DiazGranados, 2010; Sinclair \& Ashkanasy, 2005; Sinclair, 2010, 2011) and asserting its importance for management practice (e.g. Miller \& Ireland, 2005; Sadler-Smith \& Shefy, 2004; Sadler-Smith \& Burke-Smalley, 2015).

However, empirical work on intuition is not extensive (e.g. Burke \& Miller, 1999; Clarke \& Mackaness, 2001; Coget, Haag \& Gibson, 2011; Dane, Rockman \& Pratt, 2012; Fenton-O'Creevy, Soane, Nicholson \& Willman, 2011; Huang \& Pearce, 2015; Khatri \& Ng, 2000; Kickul, Gundry, Barbosa \& Whitcanack, 2009; Sinclair, 2014; Willman, FentonO'Creevy, Nicholson, \& Soane, 2001). There is a paucity of qualitative intuition research. In particular the subjective experience of intuition is poorly-understood. Intuition research therefore faces an important challenge: because much current knowledge rests largely on researchers' speculative arguments and abstract theorizations, we need to know more about intuition from the perspective of the intuitor in order to gain more direct access to the "essence" of this phenomenon (see: Merleau-Ponty, 1945/1996: vii). The objective of the research was to elicit direct, first-hand accounts from practitioners of what actually happens when they 'intuit'. 


\section{Intuition}

Scholarly interest in intuition in management dates back over three quarters of century to the work of Chester Barnard (1886-1961) and specifically the appendix ('The mind in everyday affairs') to his seminal book The Functions of the Executive (1938). In this foundational contribution Barnard distinguished between 'logical thinking processes' (“conscious thinking which could be expressed in words, or other symbols, that is, reasoning", Barnard, 1938: 302) and 'non-logical thinking processes'. The latter equates to intuition, described by Barnard on the basis of his own introspections, conjectures, and experiences as a company executive (he was President of the New Jersey Bell Telephone Company) as processes "not capable of being expressed in words or as reasoning, which are only made known by a judgment, decision or action" (Barnard, 1938: 302) and "so unexplainable that we call it 'intuition"” (Barnard, 1938: 305).

The next major milestone in intuition research is to be found in the work of Nobel laureate Herbert Simon (1916-2001). Simon's most famous contribution to administrative science was the theory of 'bounded rationality' which challenged "the widely shared assumption that humans are rational decision makers" (Alvesson \& Sandberg, 2011: 255). An elaboration of Simon's critique of the classical economic model of decision making is to be found in his 1987 Academy of Management Executive article 'Making management decisions: The role of intuition and emotions'. In this work he famously captured intuitions as "analyses frozen into habit and the capacity for rapid response through recognition" (1987: 63). This precept is fundamental to the decision researchers' view of intuition, i.e. 'intuitionas-expertise' (Sadler-Smith \& Shefy, 2004), 'intuitive expertise' (Kahneman \& Klein, 2009), or 'expert intuition' (Salas et al., 2010).

During the 1980s and 1990s management scholars became increasingly interested in intuition; there were important contributions from Agor (1986), Parikh et al. (1994), Burke 
and Miller (1999), and others. Although this research put intuition 'on the map' it was largely a-theoretic, concerned mainly with the use and effectiveness of intuition in the day-today practice of management rather than with its underlying psychological processes (Akinci \& Sadler-Smith, 2012). It was not until the first decade of the $21^{\text {st }}$ century that organizational researchers mobilized a plausible theoretical framework for making sense of intuition.

Dual-process/dual-system theories share the core assumption that human information processing is accomplished in two dissimilar but complementary ways ('analytically' or 'intuitively') by means of two substantially different and differently-evolved types of thinking "one fast and intuitive [System 1], the other slow and deliberative [System 2]" (Evans and Stanovich, 2013, p.223). This idea was captured succinctly, but metaphorically, by Evans (2003) as characterizing "two minds in one brain" (p.454). Dual-process theory has been used by organizational researchers in defining and theorizing managerial intuition, for example: (1) "intuition is a non-sequential information processing mode, which comprises both cognitive and affective elements and results in direct knowing without any use of conscious reasoning” (Sinclair \& Ashkanasy, 2005: 357); (2) “intuitions are affectively charged judgments that arise through rapid, non-conscious and holistic associations" (Dane \& Pratt, 2007: 40); (3) Chassy and Gobet (2011) capture succinctly the idea that intuition relies upon the operation of cognitive and emotional processes: "The information captured by perception, plus the knowledge activated by resonance, and the knowledge activated by emotional saliency are integrated into one single representation [an intuition] which points to a solution" (p.207). Researchers have hypothesized the antecedents of intuitive judgment (e.g. practice, implicit learning, stylistic disposition, context, etc.) as well as its direct and moderated relationships with decision making behaviours (Blume \& Covin, 2011; Dane \& Pratt, 2007; Sadler-Smith, 2015; Sinclair \& Ashkanasy, 2005). 
Neurologists have used a variety of experimental tasks (e.g. the Iowa Gambling Task) and measurement techniques (e.g. skin conductance response, SCR) to explore the bioregulatory mechanisms of intuitive decision making, as in for example Damasio and colleagues' 'somatic marker hypothesis' (Bechara et al., 1997; Damasio, 1999, Damasio et al.,1999). These insights have been complemented by research which has established a preliminary 'neural geography' of intuition (Segalowitz, 2007). For example, Lieberman, Jarcho and Satpute (2004) found that effortful, intentional explicit judgments (i.e. in domains where participants had low levels of experience and expertise) were associated with activations in a network of brain regions which comprise a 'reflective' system (referred to as the C-system), whilst intuition-based judgments (i.e. low-effort implicit judgments in domains where the participants had high experience and expertise) on the other hand were associated with activations in a variety of brain regions which together comprise a reflexive system (the X-system) including the ventro-medial prefrontal cortex (VMPC) and amygdala (Lieberman, et al., 2004; cf. Bechara, et al., 1997).

The question arises however of how far do these various insights, many of which rely on indirect descriptions and inferences, take us towards understanding intuition as experienced by the intuitor? If there is any truth in the claim that the description of a cognitive process in the first person, i.e. as the subject experiences it, is richer than any indirect description (Petitmengin, 2006) then a bottom-up, inductive mode of inquiry is likely to help us in further 'sharpening' the construct (Eisenhardt, 1989) and getting closer to the essence of intuition.

\section{Linguistics}

Dane and Pratt (2007) conceptualize intuition "both by its process (which we [i.e. they] refer to as intuiting), as well as its outcome (which we term intuitive judgments)" (p. 
36, original emphases). Dane and Pratt's (2007) foregrounding of 'intuiting' provides a helpful signpost for how to move forward in getting closer to the subjective experience of intuition. Taking the 'intuitive judgment-versus-intuiting' distinction as a starting point, this research sought a novel way to access subjects' experiences of intuition; in doing so it turned to linguistics.

In English grammar the term 'nominalization' means 'noun-like', therefore to 'denominalize' a noun is to "make it less noun-like, or turn it into a verb, adjective, or some other grammatical category" (Payne, 1997: 94). Recent well-known examples of denominalizations from noun to verb include 'to friend', and 'to Google'. De-nominalization is sometimes referred to clumsily as 'verbing'; the reverse process is nominalization (or 'nouning'), where a verb is turned into a noun, e.g. 'explain' becomes 'explanation', or indeed 'nominalize' becomes 'nominalization'. Grammarians and linguists advise that nominalizations be avoided in written English, since using the noun conceals the action, hence their exhortations that we use strong active verbs in our writing lest it falls prey to “zombie nouns" (Pinker, 2014: 50). De-nominalizing can serve useful grammatical and related purposes (see Payne, 1997: 94-96 for a summary). 'Generic de-nominalization' (Payne, 1997) forms a verb from whatever the noun refers to, hence the generic denominalizing of 'intuition' renders 'intuit' . Generic de-nominalizing (hereafter 'denominalizing') opens up the possibility that using the verb, instead of the noun, to access participants' subjective experience of intuition could render its “deep structure" (Harman \& O’Neill, 1981: 450) more transparent.

One of the benefits of de-nominalizing for accessing subjective experience is that it allows participants to retrieve and reflect on their deeper and direct personal experiences of the action instantiated in the verb rather than undertake de-contextualized and surface musings on the meaning of the noun. William James, who invented the term 'the stream of 
thought' (the title of Chapter IX of his Principles of Psychology Volume 1), was not averse to de-nominalizing in his writing, for example by turning 'cognition' into 'cognize': “we cognize relations through feeling" (1890/2007: 247, emphasis added). Interestingly James also used the verb 'intuit' in the Principles on a couple of occasions.

Hence, a novel form of inquiry for researchers who wish to understand informants' subjective experience is to ask them directly what happens when they experience intuition. Duly in this research, in attempting to get closer to informants' experiences of intuition, rather than asking them, for example 'what is intuition?' or 'what does intuition mean to you?', 'intuition' was de-nominalized and the question asked: 'what happens when you intuit?' This question formed the crux of the research, and was composed in the form of the sentence-completion task: “when I intuit...'. This approach resonates with Merleau-Ponty's phenomenology, Husserlian psycho-phenomenology, Piagetian 'becoming aware', Gendlin's psychotherapeutic method of 'focusing', and neuro-linguistic analyses of autobiographical texts (Gendlin, 1969; Merleau-Ponty, 1945/1996; Petitmengin, 1999, 2006; Tosey \& Mathison, 2010; Varela \& Shear, 1999).

\section{Method, sample and procedure}

The research method used was very straightforward: participants were asked, in the convenient setting of professional development seminars on the topic of intuition, 'what happens when you intuit?' Participants were human resource practitioners who had elected to attend a seminar for personal and professional development purposes. The seminars (five in total, lasting an hour-and-half each) were conducted by the author at various locations across the south east of the UK. The total number of participants was 124. At the beginning of each seminar following a brief introduction (i.e. before the exposition of any substantive content), participants were requested to recollect an occasion (or occasions) during which 
they had experienced an intuition. They were allowed a short time during which to reflect quietly on this experience, and from their recollections and reflections were then asked to construct a grammatically correct answer to the question 'what happens when you intuit?' They did this by completing, on a pre-printed form, the first-person statement 'when I intuit...' Participants were also invited to indicate their gender (58 per cent female, 33 per cent male, and nine percent undeclared). Completed forms were collected-in at the end of the seminar, and responses were typed-up verbatim in MS Word and transferred to MS Excel for further coding, sorting, and cross-tabulating. Participation was voluntary and anonymity was guaranteed.

For the purposes of checking the validity of the question 'What happens when you intuit?' a similar question was asked for the related phenomenon of insight, i.e. 'what happens when you have an insight?' in the same context, using the same procedure ('when I have an insight I...') with a different group of human resource participants $(N=26)$. If the question 'what happens when you intuit?' discriminates between intuition and a related but sometimes conflated phenomenon, namely insight, then participants in the 'intuit' groups ought to use different words in their responses to those used by the 'insight' group.

\section{Data analysis}

The data set was 124 individual responses; these varied in length from six words (e.g. "when I intuit I generate ideas") to 44 words (i.e. "when I intuit my gut tells me I need to seek more information and ask more questions to better understand a situation. My head starts to question what I am seeing or hearing and I feel I need to do something or take action”). There were 528 different words and 2082 words in total in the data set. As a preliminary validity check, the Hermetic Word Frequency Counter ${ }^{\mathrm{TM}}$ software (Version 14.422) was used to count the frequency of use of all words in the intuit groups' responses compared to the 
insight group's responses. These were then ranked by frequency of use, excluded definite/indefinite articles, conjunctions, and other grammatical features superfluous to the research purpose, only focusing on content words (adjectives, nouns, verbs, adverbs). In the pared-down list of the twenty most frequently used content words only the words 'feel/feeling' and 'sense' occurred in both lists. Whilst no formal criterion or threshold by which to objectively assess any overlap was used, the fact that there were only two shared words amongst the most frequently used words offered assurance that the sentence completion task 'when I intuit...' captured participants' perception of intuition rather than their perception of some related but extraneous phenomenon, such as insight.

Following this preliminary check data were analysed in a coding process as follows. All statements were read and re-read several times in order to identify key units of text. This process resulted in the decomposition of each statement into one or more units of text. A unit of text was defined as a coherent group of words which were of relevance to the phenomenon of interest (i.e. intuition). For example, the statement "When I intuit I generate ideas" decomposed easily into a single unit of text 'generate ideas'. The statement "When I intuit I make a decision or come to a conclusion based on my experience and judgement rounded-off with gut instinct, i.e. it feels right" was decomposed into the following units of text: "make a decision'; 'come to a conclusion'; 'based on my experience'; 'gut instinct'; and 'feels right'. A total of 212 units of text were identified. Participants' statements were coded in a process of reading and re-reading; this involved an iterative to-ing and fro-ing between the statements, abstracted units of text, and emerging codes.

In the final coding scheme units of text were classified into 16 first-order concepts, and labelled according to their content, for example 'Experiences', 'Gut reactions', 'Anticipating', etc., see Appendix 1 and Figure 1. The labelling of the concepts was "participant-based" (Langley \& Abdallah, 2011: 214), i.e. it reflected as closely as possible 
the words participants used. In transitioning to a higher level of abstraction the analysis moved from participant-based concepts to researcher-based themes. The concepts were classified into six superordinate themes based on a close reading and re-reading of their textual content, as follows: 'Antecedents'; 'Processes'; 'Bodily awareness'; 'Cognitive awareness'; 'Outcomes'; 'Behaviours'. Further, following close examination of the content of each of the six themes the level of abstraction in the analysis was stepped-up one more time and the six themes were classified into three superordinate aggregate dimensions, i.e. 'Intuiting', 'Intuition', and 'Implementing'. In following this sequence the analysis transitioned from participants' direct accounts (as captured in their written responses) to more abstract and theorized readings of the field data, i.e. from a descriptive to an interpretive account (Gioia, Corley \& Hamilton, 2012; Langley \& Abdallah, 2011).

The reliability of the outcome of this procedure was assessed by having two independent raters classify the units of text. The level of agreement between the two raters was assessed using Cohen's kappa ( $\kappa)($ Cohen, 1960); the computed value was $\kappa=0.77(\mathrm{SE}=$ 0.07). ${ }^{1}$ This indicated a "substantial" strength of inter-rater agreement (Landis \& Koch, 1977: 165) thus offering assurance as to the reliability of the classifications.

\section{Findings}

The overall analytical approach and the derived data structure is consistent with the method recommended by Gioia, Corley and Hamilton (2013) for inductive research as implemented, for example in Nag, Corley and Gioia (2007) and Pratt, Rockmann, and Kaufmann (2006). In keeping with this approach the data structure and sample units of text are shown in Figure 1 .

[FIGURE 1 HERE] 
The findings will now be described and interpreted in terms of the three aggregate dimensions ('intuiting', 'intuition', and 'implementing'), theme-by-theme, and illustrated with representative units of text.

\section{Intuiting}

The first superordinate dimension consisted of the antecedents and the processes of intuiting.

Antecedents (experiences; patterns): this theme captured the antecedents of intuiting in two first-order concepts, 'experiences' and 'patterns'. Participants wrote about how they use past experiences to make present judgments and inform their actions, for example (Note: for economy of space, individual quotes are run together in the reporting below, numerals in brackets indicate which participant is being quoted):

"When I intuit: I use past experiences to make judgements for the present (participant 98); I draw on my past experiences (97); [I use] facts in the back of my mind (86); I think about past experience, a similar situation, what I did, what I've see others do, what's likely to happen, what is likely to work (48); elements of my experience come together to shape my thoughts and actions (19)."

Participants wrote about intuiting as recognising cues and matching an observed pattern against a previously encountered pattern, for example:

"When I intuit: I recognise cues that inform a thought [or] feeling; (31); I interpret body language deciding where I have come across similar person / 
situation (42); I draw on previous experience of similar situations and think how they worked out (37)".

Previous experience and pattern matching are connected: past experiences and prior learning provide the intuitor with the informational substrates that support recognition and pattern matching.

Processes (automatic; subconscious; fast): this theme captured the processes of intuiting in three first-order concepts 'automatic', 'subconscious', and 'fast'. Although participants wrote about experience and pattern recognition (see above), they also acknowledged that intuitive 'knowing' is a low-effort process, achieved with little conscious, rational thinking; for this reason the first-order concept was labelled 'automatic', for example:

"When I intuit: I know[ing] something without having thought it through (8); I can't always explain [a] decision rationally; I know something is wrong because it just is (76); I don't need a rationale (92); I make a decision without fully understanding how (32); I don't have to think about it (63); I understand instinctively without the need for conscious reasoning (66); I know the right answer but can't explain why. It is just right (68); I come up with a solution but don't know specifically how I arrived at it (89)."

Automatic processing was the most prevalent first-order concept (see Appendix 1). Processing is outside of conscious awareness, one participant described it as being "under the surface" (2), further examples were: 
"When I intuit: I sense an unsaid (15); I process a massive amount of information at a primitive level (42); I feel as though [the] answer/response appears from nowhere (77); I am never really sure where the answer comes from (27).”

It also was evident in participants' writings that these inaccessible processes often are fast, for example:

"When I intuit: it happens quickly (86); I unconsciously and quickly inform my view / perception (4); [it is] my immediate reaction (16)."

Participants acknowledged the role of experience and pattern matching in intuiting and that the mechanisms and processes are not readily available to introspection. As depicted in these data 'intuiting' is automatic, rapid, and subconscious, and occurs in response to the matching of cues against informational substrates built-up by past experiences and prior learnings. This finding is synthesized into the definition of intuition as reported in the 'Discussion' section below.

\section{Intuition}

Intuitions emerge into consciousness as 'bodily awareness' and 'cognitive awareness'.

Bodily awareness (gut reactions; feelings): this theme was comprised of two first-order concepts 'gut reactions' and 'feelings'. Both concepts captured the perception that intuitions were somatic (i.e. of, or relating to, the body) but they differed in terms of the degree of specificity with which this awareness could be located: the visceral 'gut reaction' first-order concept captured a more specifically-located bodily awareness whereas the 'feelings' first- 
order concept captured a less specifically-located, but nonetheless deemed to be bodily, awareness. An example of the former is:

"When I intuit I get: feelings in my stomach (10); excited buzz in my stomach (18); weird feeling in my stomach (58); butterflies (92)."

It is noteworthy that participants used metaphors to describe these bodily awarenesses, for example "buzz", and "butterflies". 'Gut reactions' was the third most common first-order concept (see Appendix 1). In other instances intuition was described in terms categorized as bodily awareness but less precisely located, i.e. as a more general 'feeling' state, for example:

"When I intuit I get a: clear feeling (20); feeling of great satisfaction and ease (23); warm fuzzy feeling inside (88); whole body feeling (113); strange feeling (82)."

In participants' writings repeated articulations were encountered on the theme that intuition is somatic; this is captured under the general label of 'bodily awareness'.

Cognitive awareness (sense; mental images): as well as emerging as a bodily awareness (see above) intuition was also expressed in terms that were categorized as a 'cognitive awareness'. In this theme participants wrote about intuition in two ways, first as an inscrutable 'sense', for example: 
"When I intuit I: get a sense for something (25); get a sense of something coming together (synthesis) (7); get a sense of something bigger than what the words I've heard exactly mean (21)."

On the other hand some participants associated intuition with mental images (i.e. mental representations which may occur in various modalities) in visual and auditory modes, for example as 'voice' and 'mind's eye':

"When I intuit I: see 'it' in my mind's eye (7); get a picture in my mind (21); listen to that small voice in my head (28); get an inner voice which I hear and consider [to be] right course of action" (50).

It was evident from some participants' writings that they perceived intuition as occurring as a cognitive 'sense' or more well-defined 'mental image'; these two first-order concepts were captured under the theme of 'cognitive awareness'. The bodily and cognitive aspects of intuitive affect are synthesized into the definition of intuition as reported in the 'Discussion' section below.

\section{Implementing}

Intuitive judgements were implemented as behavioural responses (for example, taking a decisive action, anticipating a predicted outcome) based on the intuitor's interpretation of the intuitive signal or insight (for example, to approach or avoid a person or situation, be able to 'see' connections which were previously not apparent). It should be noted that the term 'Implementing' is not intended to indicate that an intuition is necessarily 'heeded'; acting in 
response to an intuition might mean, paradoxically, that the intuition is consciously supressed (for example by the intervention of rational processing, see below).

Outcomes (negative signal; positive signal; insight): this theme captured two types of outcomes: (1) a signal, positively- or negatively-valenced; (2) novel or creative perceptions and connections referred to as 'insight'.

Intuition provided signals which served as positive or negative evaluations of a decision, situation, or person; these translate into "approach versus avoidance behavioural responses" (Lieberman, 2001: 127). For example participants interpreted positively-valenced intuitions as a signal for the 'right thing' to do:

"When I intuit: I know it's the right thing to do (1); I know instinctively what to do" (7); I'm in the right place or with the right people (23); I [have a] hunch that something feels right (24); I [have a] strong sense of the 'right' path / decision to take (26); something clicks inside that I recognise as clearly right (5); I feel at peace and comfortable (54); I [have a] sense of what is right" (70).

Intuition as a positive signal was the second most common first-order concept (see Appendix 1). Negatively-valenced intuitions were interpreted as signalling that something might be wrong about a decision, situation, or person, for example:

"When I intuit: I know instinctively what to not do (7); I sense something does not quite fit (15); I [have a] negative immediate reaction (16); I start to think that 
there is something (59); things just don't feel right (9); I know something is wrong (56)."

As well as affording positively- and negatively-valenced signals, intuition also yielded outcomes judged to be insightful and creative, for example:

"When I intuit: I generate ideas (114); idea[s] bubble up in to my awareness (3); [I have a] flash of insight or inspiration (7); my mind opens up with a new insight (11); ideas flow, patterns emerge, insights [and] inspirations grab me (51); I make productive connections between previous unconnected or apparently unrelated ideas (105); lots of ideas flow out (109)"

The language used to describe these creative intuitions was replete with metaphors: "bubble up", “inspirations grab", “flash", "mind opens up", and "flow”.

Behaviours (anticipating; deciding; judging; questioning): this theme captured the intuitors' behavioural responses. Intuition enabled subjects to anticipate events (interestingly only one participant described it as a "sixth sense" [61]), for example:

"When I intuit: [I have a] feeling something is going to happen (17); I sense that things will work-out (23); [I have] a feeling about [what] happens before it happens (67); [I have an] understanding of what is about to happen (9)"

Intuitions also supported decision making (deciding), for example: 
"When I intuit: I make a decision (34); [I have a] strong feeling of the direction to go in (6); I act with certainty (92); [I am able to] solve a problem (107); [I have] an indication to act in a certain way (37); create scenarios and make plans [and] decisions (55)"

'Judging' involved weighing-up the 'pros' and 'cons' of a decision. Participants also recognised that implementing an intuitive judgement entails risks and uncertainties (i.e. they are forward projections based on subjective evaluations), for example:

"When I intuit: I come to a conclusion (81); I make a judgement call (97); I cannot rationalise an absolute decision so I make a casting vote based on intuition (38); I make a judgement on what is right or wrong (71); I use my judgement to make a decision (87); I risk a conclusion that may pay-off (90).”

Intuitions also evoked further questions which required the intervention of rational analysis as a counter-balance to an intuitive judgement, for example:

"When I intuit: I ask myself what's really going on here (50); I need to seek more information and ask more questions (106)."

Participants wrote about balancing intuition by 'asking questions', or weighing-up the intuitive versus non-intuitive components of a decision. Intuitions provide positive or negative subjective evaluations and insights that guide subsequent behaviours. This finding is synthesized into the definition of intuition as reported in the 'Discussion' section below. 
Supplementary analysis on the use of metaphor: As depicted in the above interpretation, participants wrote about intuition in a variety of different idioms both literal and metaphorical. Examples of the use of metaphorical language in 'intuiting' were the knowledge was "at the back of my mind", and there was "something under the surface". In the 'intuition' dimension the language used was replete with embodied metaphors, for example "excited buzz", "butterflies", "mind's eye", and "inner voice". Metaphors were used in 'implementing' for example to express the "right path", how choices were "weighed-up", being 'grabbed' by inspirations, and ideas that "bubbled up". In order to explore variations in usage it was decided to quantify the use of metaphors in each of the three aggregate dimensions.

The frequency of use of metaphorical language was the number of units of text containing a metaphor. The proportions of metaphors used in each of the dimensions (approximating to the ratio of metaphorical to literal language use) were as follows: intuiting, seven metaphorical (11 per cent), 56 non-metaphorical (89 per cent); intuition, 18 metaphorical (33 per cent), 37 non-metaphorical (67 per cent); implementing, 14 metaphorical (15 per cent), 80 non-metaphorical ( 85 per cent). This comparison revealed intriguing differences in the use of metaphor across the three dimensions 'intuiting', 'intuition', and 'implementing'. In the 'intuition' dimension a third of the units of text contained metaphorical language, whilst in the 'intuiting' and 'implementing' dimensions there were significantly fewer metaphors. These differences were statistically significant at the five percent level $\left(\chi^{2}=8.91 ; \mathrm{df}=2 ; p=0.012\right)$.

\section{Discussion}

An empirical contribution of this research is a phenomenologically-based definition of intuition, namely: positively-or negatively-valenced affective states, manifesting cognitively 
or somatically, arising automatically, rapidly and subconsciously, informed by prior learning and experiences, affording subjective evaluations and guiding subsequent behaviours. In terms of key distinctions in the intuition process, previous research separates 'intuiting' (process) from 'intuitive judgement' (outcome) (Dane \& Pratt, 2007), see Figure 2a. The present research has unpacked the subjective experience of intuition further, revealing it to have two aspects labelled 'bodily awareness' and 'cognitive awareness'. In doing so the research identifies a conceptual bridge between intuition's antecedents (pre-intuition) and its behavioural outcomes (post-intuition); the subjective experience of intuition is at the pivot point of the process, see Figure $2 \mathrm{~b}$. An ancillary point is that the inductively-derived term 'implementing' subsumes Dane and Pratt's (2007) 'intuitive judgment' whilst capturing a wider range of potential outcomes.

\section{[FIGURES 2a\&b HERE]}

The model is consistent with the view of 'intuition-as-expertise', 'intuitive expertise' and 'expert intuition' (Sadler-Smith \& Shefy, 2004; Kahneman \& Klein, 2009; Salas et al., 2010) and consequently also with Klein's recognition-primed decision (RPD) model, namely: ‘intuiting' entails rapid, non-conscious processing based on past experiences and prior learnings. In recognition-primed decision making (Klein, 1998; 2003; Klein, Calderwood \& Clinton-Cirocco, 1988) decision makers recognize salient cues (as one of the participants wrote: "I recognize cues" [31]) and match these to extant patterns and prototypes of similar situations or people (for example, "what's likely to happen, what's likely to work" [48]). In the RPD model behavioural responses in the form of 'action scripts' are executed on the basis of a matching process (Klein, 2003). Furthermore, the outcomes of intuiting reflect a possible source of distinction and line of demarcation between expert intuition and creative 
intuition (Gore \& Sadler-Smith, 2011). Positive or negative signals reflect intuitive expertise whereas 'insightful' outcomes manifest creative intuition.

Intuiting, as far as the intuitor is concerned, appears to be largely automatic involving little in the way of effortful cognition (see Stanovich, 2009). It is recognized that attempts can be made to trigger intuition by "clear intention" (Sinclair, 2010: 380) and introspecting on the intuitive assessment of a situation (e.g. 'what does your gut tell you?'), or in the instinctive moral reactions evoked by an ethical dilemma, (see Haidt [2001] for examples of stimulus materials) and by cultivating “intuitive receptivity” (Tomasino, 2011: 247). Subjects "understand instinctively without the need for conscious reasoning" (66), so much so that the experience of intuiting provides evaluations arrived at with minimal conscious cognition ("it is just right" [68]) (cf. the merits of 'unconscious thought', see: Dijksterhuis, 2004). The affect associated with the intuitive signal indicates 'rightness' or 'wrongness' (Sinclair, Ashkanasy, Chattopadhay \& Boyle, 2002). Furthermore, the processes of intuiting are fast. Whether or not the intuitive response turns out to be effective is likely to depend on the intuitor's situational awareness (Klein et al., 1988), her expertise (Ericsson, Prietula \& Cokely, 2007), the validity of the decision making task or environment (i.e. how predictable outcomes are on the basis of the perceived cues, see: Kahneman \& Klein, 2009), and the “dynamic interplay” between intuition and analysis (Hodgkinson \& Healey, 2011: 1503).

This research addresses a particular shortcoming in current theorizations by shedding light on the nature and role of intuitive affect. Prior research is uneven in acknowledging affect's role in intuitive judgment. For example, the Simonian position is that intuitions are analyses that have been 'frozen into habit' which give decision makers the capacity for "rapid response through recognition" (Simon, 1987: 63). In the same vein, Klein's (2003) standpoint is largely cognitive: intuitions are fundamentally 'non-conscious analyses'. These are essentially expertise-based views of intuition, however Sinclair and Ashkanasy (2005) 
note that "proponents of experience-based intuition [i.e. expertise] focus solely on the cognitive elements of the construct" (p.358). Consequently intuitive affect is sometimes overlooked or treated as a something of 'black-box' within the intuition-as-expertise view (Sadler-Smith \& Shefy, 2004).

Sinclair and Ashkanasy (2005) use affect as a broad 'umbrella' term for all emotional states including intense and short-lived emotions, lingering non-specific mood, and subtle transient affective feelings. Concurring fully with the emphasis these researchers accord to affect in intuition, these data suggest that intuitive affect is in fact somewhat narrower than Sinclair and Ashkanasy (2005) seem to imply. Moreover, whilst Sinclair and Ashkanasy (2005) specify affect as antecedent (not an integral part of intuiting, but its trigger or inhibitor), process component (integral part), and outcome (confirmation feeling) these data suggest that affect manifests in mainly the outcome (i.e. 'intuition') rather than in the process itself ('intuiting') or in the behavioural follow-through ('implementing'), see Figure $2 \mathrm{~b}$. These findings sharpen understandings of the nature and role of intuitive affect and point to a need for further multi-method laboratory as well as field research to pinpoint these phenomena more precisely (see below).

Dane and Pratt (2007) use the term 'affectively-charged' in their definition of intuition and offer a discussion of the way that the "affective tenor of intuitive judgments" (p.39) affects decision making (see also: Dane \& Pratt, 2009). Since intuition "operates at the nexus of thinking and feeling" (Hodgkinson et al., 2009: 278) viewing cognition and feeling as wholly distinct entities (e.g. Panksepp, 2003) is potentially unhelpful in intuition research, whereas conceiving the boundary between them as being rather more permeable opens the way to a potentially richer conceptualization. Clore (1992) is somewhat helpful in this regard in suggesting that feelings can be grouped into three categories: (1) affective feelings: valenced subjective experiences encompassing moods and emotions; (2) bodily feelings: 
reflections of physical processes such as hunger or pain; (3) cognitive feelings: experiential states that accompany cognitive processes such as feelings of familiarity (Clore, 1992; Greifeneder, Bless, \& Pham, 2010). Whilst the exact demarcations suggested by Clore (1992) do not map exactly onto intuition (since this was not his intention), the notion of different types of feeling states and the specific proposal that 'cognitive feeling' need not be an oxymoron is a helpful insight.

Whilst some intuition researchers have distinguished between the level (high-low) and valance (positive-negative) of intuitive judgments (Dane \& Pratt, 2009), the general use of the term 'affect' can be somewhat imprecise, for example 'intuitive affect' is depicted as a unitary phenomenon, most often equated with 'gut feel' (Agor, 1986; Burke \& Miller, 1999; Hayashi, 2001; Khatri \& Ng, 2000). The findings reported here support an alternative and more nuanced view. The experiential state of 'intuition' is revealed as having two elements: 'bodily awareness' and 'cognitive awareness'. There is supporting evidence from prior research for this assertion in that greater reliance on cognitive feelings is associated with higher levels of faith in intuition (Keller \& Bless, 2008). Cognitive feelings are one way in which the products of subconscious processes become registered, articulated, and interpreted (Greifeneder, et al., 2010). 'Affect infusion' (Forgas, 1995) might therefore entail bodily or cognitive feeling states. This joint view accommodates a broader conceptualization of intuition beyond equating it solely with 'gut feelings', separates intuitive affect from primary emotions (e.g. fear), and also bridges relevant literatures on somatic, affective, and cognitive states (e.g. Baumann \& Kuhl, 2002; Damasio, 1999; Dunn, et al. 2010; Forgas, 1995; Slovic et al., 2004).

A corollary of the above is that intuitive affect may be delineated in terms of 'locus' (bodily/cognitive), 'level' (high/low), and 'valence' (positive/negative); on this basis a $2 \times 2$ $\times 2$ typology of intuitive affect is proposed, see Figure 3. For example, a positively-valenced, 
high-level intuitive affect with a cognitive locus is a 'strong positive hunch' (rear top right cell in Figure 3), whereas a negatively-valenced, low-level intuitive affect with a bodily locus is a 'weak negative gut feeling' (front bottom left cell). This typology also raises interesting questions, which this research did not set out to answer, as to whether or not the level of the affective charge can in fact be 'zero' in intuitive judgment (Sinclair, 2010).

\section{[FIGURE 3 HERE]}

Participants frequently used metaphors to express what happens when they intuit. Metaphors are a linguistic means of articulating and interpreting experiences, and substitute for a tacit and "deeper knowledge" (Tsoukas, 1991: 582). The metaphoric idiom involves the transfer of information from a familiar domain (source) to a new domain (target) in order to express similarities between what a word normally designates in its source domain and what it is intended to designate in its target domain (Lakoff \& Johnson, 1999). Metaphors are pervasive in everyday life, not only in language but also in thought and action to the extent that how we think and act is "fundamentally metaphorical in nature" (Lakoff \& Johnson, 1980: 3). Furthermore, metaphors are not only a way in which the experiential/intuitive system "encodes reality" (Epstein, 2011: 39), they are one of the principal ways of framing and understanding organizational life (Morgan, 1980).

Complex metaphors such as 'organizational identity' (Cornelissen \& Kafouros, 2008) can be composed of several primary metaphors (Grady, 1999). Primary metaphors permit the expression of an internal subjective experience; they are relevant for intuition research because they are grounded in source domains related to embodied experiences (e.g. temperature, size, vision, orientation, etc.), constituting experientially-based metaphorical mappings, or 'correlations' from every-day experiences (Lakoff \& Johnson, 1980). For 
example, the mapping 'up is good whereas down is bad' as in the metaphor 'things just don't stack up" (orientation) signifies that the situation is 'not up' and therefore 'not good'; likewise, "I see what you mean” (vision) signifying 'seeing-as-knowing' (Feldman, 2008). Primary metaphors are elemental in that it is not possible to regress any further to more 'primordial' descriptions (Cornelissen \& Kafouros, 2008; Gibbs, 2006).

Using these various ideas to support an analysis of the metaphorical content of participants' writings about intuition it was possible to discern two further discoveries: (1) participants did indeed use primary metaphors (for example, “warm”, “path”, "flow”, "flash", "weigh", "voice", etc.) ; (2) metaphors were more prevalent in the writings used by participants to express 'intuition' than in 'intuiting' and 'implementing'. The core experience of intuition -the central element in the three-phase model (Figure 2b) - manifests as bodily feelings and cognitive feelings which by their nature are subjective and inscrutable. This research ventures that metaphorical expressions are deployed in lieu of literal expression and substitute for deeper knowledge of the intuitive subjective state. A contrast was observed between the use of literal and metaphorical language in intuition versus intuiting and implementing. Participants speculated as to the supposed antecedents of intuition (attributing this to concrete entities such as 'experience' and assumed automatic processes which reside somewhere in the 'subconscious'), and likewise interpreted outcomes and behavioural responses literally. This distinction may to help explain why metaphors occurred less frequently in the units of text associated with the intuiting and implementing phases. It is reasonable to argue that the experience of intuition is more easily articulated and interpreted in terms of primary metaphors "grounded in source domains related to our embodied experiences" (Cornelissen \& Kafouros, 2008: 2) than literally. This is an area for further linguistic and phenomenological inquiry. 
Finally, this research corroborates theoretical distinctions that have been proposed between expert intuition and creative intuition. In participants' writings it was possible to discern two types of intuition: first, expert intuition (cf. Salas et al., 2010) more particularly in relation to antecedents of intuiting (experience and patterns); second, creative intuitions (Dane \& Pratt, 2009; Gore \& Sadler-Smith, 2011) especially in relation to insight in the implementing of intuition. This finding may offer a useful pointer as to the nature of the relationship between intuition and insight, for example a plausible sequence is from intuiting, to cognitive awareness, to creative problem solving via insight. The history of scientific discovery is replete with compelling first-hand subjective accounts of major scientists, such as Poincaré, Darwin and Einstein, having insightful moments that were preceded by creative intuitions (Ghiselin, 1952/1985; Miller, 1992; Sternberg \& Davidson, 1995; Wallas, 1926). Researching the role of creative intuitions in scientific and technical breakthroughs could develop new understandings of the cognitive and affective processes implicated in innovation and new production development, especially at the front-end of these processes (Hyppanen, 2014) and in so-called 'edging' (i.e. "being exposed to a situation requiring stretch and extra cognitive or emotional effort”) (Teerikangas \& Välikangas, 2014: 77).

\section{Implications, limitations and future research}

As noted in the 'Introduction', intuition research in management is characterized by a scarcity of qualitative work. This research is one of a small handful of studies in this area and has implications for intuition theory and hints at several new research directions as follows: (1) the research sharpens and elaborates the way intuition is conceptualized, but in contrast to other recent research it has done so directly, 'bottom-up' so to speak, from the perspective of data and experience rather than indirectly from theory; (2) researchers have previously equated intuitions with 'gut feelings' (e.g. Burke \& Miller, 1999; Hayashi, 2001) however 
these data suggest this might be insufficient. A more helpful framing is a general category of 'intuitive affect' within which bodily feelings (referred to colloquially as 'gut feel') and cognitive feelings (referred to colloquially as 'hunch' or 'vibe') comprise two separate aspects of the subjective experience of intuition; (3) it expands Dane and Pratt's (2007) 'intuiting' and 'intuitive judgment' distinction (Figure 2a) into three elements, 'intuiting', 'intuition', and 'implementing' (Figure 2b) which offers a tentative three-phase model; (4) there is evidence that the deeper, subjective experience of intuition, instantiated in bodily and cognitive feelings, is articulated and interpreted using the linguistic idiom of metaphor.

These various contributions should be seen in-context: we know a considerable amount about what constitutes 'intuitive expertise' (Dreyfus \& Dreyfus, 2006; Kahneman \& Klein, 2009; Klein, 1998, 2003; Klein et al., 1988; Salas et al., 2010) but markedly less about how intuitive expertise is embodied and enacted in organizational settings. By foregrounding the embodiment and implementing of intuition, this research connects organizational behaviour research with emerging streams of more process-oriented inquiry, including phenomenological, practice-based, ethnomethodological, discourse, and linguistically- and sociolinguistically-oriented studies. These various sub-fields offer theories and methods that could be used for new studies that capture the experience of intuition phenomenologically, ethnographically, discursively, and performatively.

It is evident from these data that subjects' 'awareness' of intuition is the focal element of their experience. It is surprising therefore that, as noted in above, comparatively little theoretical or empirical attention has been given to understanding this aspect of the phenomenon (Sadler-Smith \& Shefy, 2007). We need to know more about the detailed nature of intuitive affect over-and-above mere attributions to 'gut feelings', and also explore: (1) whether different feeling states arise under different conditions; (2) the possibility of individual differences in the subjective experience of intuition, including individuals' 
sensitivities to their bodily state (Dunn et al., 2010), variability in the modalities in which intuition presents itself (Miller, 1992; Vaughan, 1979), perceptions of where the 'felt sense' (Gendlin, 1969) of intuition is located (e.g. by means of 'body mapping' on a mannequin or other means of representing the human form); (3) the neural correlates (via functional neuroimaging studies) of the various aspects of intuitive affect uncovered in this research (see Lieberman et al., 2004; Segalowitz, 2007).

A limitation of the sample of was that participants (human resource practitioners) selfselected to attend the seminar, hence they may have been well-motivated to describe intuition and biased in favour of doing so. Future research might overcome this limitation by using randomly selected samples. The use of convenience sampling limits the generalizability of the research therefore it would be interesting to undertake similar research with other occupational groups who use intuition in their decisions such as entrepreneurs (Blume \& Covin, 2011; Mitchell, Friga \& Mitchell, 2005; Sadler-Smith, 2015) as well with as management students. The questioning technique was limited in the extent to which it was able to access the unconscious processes from which intuitions emanate; that said, the elicitation and analysis of metaphors may be one way to glimpse these processes and help intuition researchers, as well as practitioners, to 'see through a glass darkly' into the deeper structure of their intuitions. $^{2}$

The study of managers' experiences of intuition promises to be a fertile area for phenomenological field work. De-nominalization was deployed so that participants might retrieve and reflect on their direct personal experiences of the object (intuition) instantiated in the verb (intuit). The research did not seek to distinguish between expert and creative intuitions (any distinctions that arose did so inductively from the data) however an area for future inquiry might be to apply de-nominalization, or similar technique, to try to understand specifically what happens when someone 'expertly intuits' versus 'creatively intuits'. 
Likewise, the same approach could also be readily applied by researchers who wish to understand informants' subjective experiences of other phenomena and processes (e.g. 'leading', 'deciding', etc.). This research presents a novel methodological contribution which complements other approaches (e.g. Petitmengin 2006, 2014) and expands the current inventory of intuition research methods (see: Sinclair, 2014 for an up-to-date review).

A further limitation of the research is the fact that given the author's theoretical positioning it was difficult not to view the data through a dual-process lens. A number of researchers have challenged the pre-eminence of the dual-process paradigm (e.g. Gigerenzer, 2010; Keren, 2013; Osman, 2004), and proposed alternative 'System 0’ (Dreyfus, 2014), 'unimodel' (Kruglanski, 2013), and even 'System 3' (Li, 2014) conceptualizations. Whilst it is acknowledged that these alternative views exist there are no compelling reasons, either conceptual or empirical, for the abandonment of the dual-process position in favour of a single- or tripartite-theoretic view. The baseline position from which this research was conducted resonates with that of Kahneman (2011) and Evans and Stanovich: (2013a\&b), namely: "fast processing requiring little resources must combine with another kind of processing that is slow, effortful, and resource intensive" (Evans \& Stanovich, 2013a: 268) and that this "dual-processing distinction is supported by much recent evidence in cognitive science" (Evans \& Stanovich, 2013b: 223).

Although the research did not set out explicitly to elicit or study metaphors the method used proved to be a quick and efficient means to access them. Its limitation was that participants were not asked expressly to use metaphors; on the other hand by not deliberately framing the question to induce metaphorical expression the research ended-up eliciting 'natural language' use of metaphors (Pennebaker, Mehl \& Niederhoffer, 2003). Future research might explore this aspect of articulating and interpreting intuition by framing questions in such a way as to deliberately evoke metaphors in written texts or spoken 
utterances. Such research might also explore the relationship between metaphors and intuitive imageries which present in a variety of modalities (e.g. olfactory, auditory, visual, etc.).

The findings of this research point to a number of implications for management development and management practice. First, this research corroborates that intuition is relevant in human resource practice (Miles \& Sadler-Smith, 2014), therefore human resource practitioners (and managers more generally) need to develop an awareness of the pitfalls and potential of intuitive judgement. Second, managers should be helped to appreciate that there are different types of intuition, and particularly be able to discern between expert intuition and creative intuitions in order that they can recognise the approach/avoid signals that expert intuition offers and the insights that creative intuitions can provide. Third, as well as there being different types of intuition, managers also need to appreciate that intuition can manifest both somatically (as a 'gut feeling') and cognitively (as a 'hunch') and that these subjective states should be acknowledged and listened to, but not necessarily heeded. Fourth, the use of intuitions in organizational decision making is confounded by the fact that intuitive judgements are highly subjective, however encouraging and eliciting metaphorical expression of intuitions could help managers articulate, interpret and enact their own, and others', intuitions, and thereby enable sense-making and support group decision making and organizational learning processes (Crossan, Lane \& White, 1999). Managers need to build and be confident in using a personal 'lexicon for intuition'. Finally, it is important that organizations create the conditions for intuitive expertise to develop (e.g. through experience, coaching, and feedback) and for creative intuitions to flourish (e.g. by allowing the mental space for unconscious processes to operate and generate insights that can lead to creative problem solving, invention, and innovation). 
This research has sought to get closer empirically to the subjective experience of intuition. In embracing this challenge a novel qualitative method was applied which used the linguistic device of de-nominalization to access intuition's deeper structure. By paying very close attention to what practitioners wrote about their experiences of intuition this research has developed a model which positions the subjective experience of intuition at the fulcrum of intuiting (pre-intuition) and implementing (post-intuition). Through replication and extension with different samples in different contexts, by developing and elaborating the linguistic method, designing new instruments based on these raw data, and proposing and testing new hypotheses, this research could have important implications for how we understand the essence of a phenomenon which is seen increasingly as pivotal in organizational practice.

\section{Funding}

This research received no specific grant from any funding agency in the public, commercial, or not-for-profit sectors.

\section{Notes}

${ }^{1}$ I used an online calculator to compute the value of Cohen's $\kappa:$ https://www.statstodo.com/CohenKappa_Pgm.php .

\footnotetext{
${ }^{2}$ I am grateful to one of the reviewers of this article for alerting me to this vivid metaphor from 1 Corinthians 13:12.
} 


\section{References}

Agor WH (1986) The logic of intuition: How top executives make important decisions. Organizational Dynamics 14(3): 5-18.

Akinci C and Sadler-Smith E (2012) Intuition in management research: A historical review. International Journal of Management Reviews 14(1): 104-122.

Alvesson M and Sandberg J (2011) Generating research questions through problematization. Academy of Management Review 36(2): 247-271.

Barnard IC (1938) The Functions of the Executive. Cambridge: Harvard University Press. Baumann N and Kuhl J (2002) Intuition, affect, and personality: unconscious coherence judgments and self-regulation of negative affect. Journal of Personality and Social Psychology 83(5): 1213-1223.

Bechara A, Damasio H, Tranel D and Damasio AR (1997) Deciding advantageously before knowing the advantageous strategy. Science 275(5304): 1293-1295.

Blume BD and Covin JG (2011) Attributions to intuition in the venture founding process: Do entrepreneurs actually use intuition or just say that they do? Journal of Business Venturing 26(1): 137-151.

Burke LA and Miller MK (1999) Taking the mystery out of intuitive decision making. Academy of Management Executive 13(4): 91-99.

Chassy P and Gobet F (2011) A hypothesis about the biological basis of expert intuition. Review of General Psychology 15(3): 198-212.

Clarke I and Mackaness W (2001) Management 'intuition': an interpretative account of structure and content of decision schemas using cognitive maps. Journal of Management Studies 38(2): 147-172. 
Clore GL (1992) Cognitive phenomenology: Feelings and the construction of judgment. In: Martin LL and Tesser A (eds.) The Construction of Social Judgments Hillsdale, NJ: Erlbaum, 133-163.

Coget JF, Haag C and Gibson DE (2011). Anger and fear in decision-making: The case of film directors on set. European Management Journal 29(6): 476-490.

Cohen J (1960) A coefficient of agreement for nominal scales. Educational and Psychological Measurement 20: 37-46.

Cornelissen JP and Kafouros M (2008) The emergent organization: Primary and complex metaphors in theorizing about organizations. Organization Studies 29(7): 957-978

Crossan MM, Lane HW and White RE (1999) an organizational learning framework: From intuition to institution. Academy of Management Review 24(3): 522-537.

Damasio AR, Everitt BJ and Bishop D (1996) The somatic marker hypothesis and the possible functions of the prefrontal cortex [and discussion]. Philosophical Transactions of the Royal Society B: Biological Sciences 351(1346): 1413-1420.

Damasio AR (1999) The feeling of what happens: Body, emotion and the making of consciousness. London: Vintage.

Dane E and Pratt MG (2007) exploring intuition and its role in managerial decision making. Academy of Management Review 32(1): 33-54.

Dane E and Pratt MG (2009) conceptualizing and measuring intuition: A review of recent trends. In: Hodgkinson GP and Ford JK (eds.) International Review of Industrial and Organizational Psychology 24. Chichester, UK: Wiley, 1-40.

Dane E, Rockmann KW and Pratt MG. (2012) When should I trust my gut? Linking domain expertise to intuitive decision-making effectiveness. Organizational Behavior and Human Decision Processes 119: 187-194. 
Dijksterhuis A (2004) Think different: the merits of unconscious thought in preference development and decision making. Journal of Personality and Social Psychology 87(5): 586-598.

Dörfler V and Ackermann F (2012) Understanding intuition: The case for two forms of intuition. Management Learning 43(5): 545-564

Dreyfus SE (2014) System 0: the overlooked explanation of expert intuition. In: M Sinclair (ed) Handbook of Research Methods on Intuition. Cheltenham: Edward Elgar, 15-27.

Dreyfus HL and Dreyfus SE (2005) Peripheral vision expertise in real world contexts. Organization Studies 26(5): 779-792.

Dunn BD, Galton HC, Morgan R, Evans D, Oliver C, Meyer, M and Dalgleish T (2010) Listening to your heart: How interoception shapes emotion experience and intuitive decision making. Psychological Science 21(12): 1835-1844.

Eisenhardt KM (1989) Building theories from case study research. Academy of Management Review 14(4): 532-550.

Epstein S (2011) The influence of valence and intensity of affect on intuitive processing. In M Sinclair (ed) Handbook of Intuition Research. Cheltenham: Edward Elgar, 37-51 Epstein S, Pacini R, Denes-Raj V and Heier H (1996) Individual differences in intuitiveexperiential and analytical-rational thinking styles. Journal of Personality and Social Psychology 71(2): 390-405.

Ericsson KA, Prietula MJ and Cokely ET (2007) The making of an expert. Harvard Business Review July-August: 115-121.

Evans JStBT (2003) In two minds: Dual-process accounts of reasoning. Trends in Cognitive Sciences 7(10): 454-459.

Evans JStBT and Stanovich KE (2013a) Theory and meta-theory in the study of dual processing reply to comments. Perspectives on Psychological Science 8(3): 263-271. 
Evans, JStBT and Stanovich KE (2013b) Dual-process theories of higher cognition advancing the debate. Perspectives on Psychological Science 8(3): 223-241.

Feldman J (2008) From molecule to metaphor: A neural theory of language. Ambridge, MA.: MIT Press.

Fenton-O’Creevy M, Soane E, Nicholson N and Willman P. (2011) Thinking, feeling and deciding: The influence of emotions on the decision making and performance of traders. Journal of Organizational Behavior 32(8): 1044-1061.

Forgas JP (1995) Mood and judgment: the affect infusion model (AIM). Psychological Bulletin 117(1): 39-66

Gendlin ET (1969) Focusing. Psychotherapy: Theory, Research \& Practice 6(1): 4-15.

Ghiselin B (1952/1980). The Creative Process. Berkeley: University of California Press. Gibbs R (2006) Embodiment and Cognitive Science. Cambridge: Cambridge University Press.

Gioia D, Corley KG and Hamilton AL (2013) Seeking qualitative rigor in inductive research: Notes on the Gioia methodology. Organizational Research Methods 16(1): 15-31.

Gigerenzer G (2010) Personal reflections on theory and psychology. Theory \& Psychology 20(6): 733-743.

Gore J and Sadler-Smith E (2011) Unpacking intuition: A process and outcome framework. Review of General Psychology 15(4): 304-316.

Grady J (1999) A typology of motivation for conceptual metaphor: Correlation vs. resemblance. In: Gibbs RW and Steen GJ (eds) Metaphor in cognitive linguistics. Amsterdam: John Benjamins, 79-100.

Greifeneder R, Bless H and Pham MT (2010) When do people rely on affective and cognitive feelings in judgment? A review. Personality and Social Psychology Review 15(2): 107-141. 
Haidt J (2001) The emotional dog and its rational tail: A social intuitionist approach to moral judgment. Psychological Review, 108(4): 814-834.

Harman RL and O'Neill C (1981) Neuro Linguistic Programming for counsellors. The Personnel and Guidance Journal, 59(7): 449-453.

Hayashi AM (2001) When to trust your gut. Harvard Business Review 79(2): 59-65.

Hodgkinson GP and Clarke I (2007) Exploring the cognitive significance of organizational strategizing: A dual-process framework and research agenda. Human Relations 60(1): 243255.

Hodgkinson GP and Healey MP (2011) Psychological foundations of dynamic capabilities: reflexion and reflection in strategic management. Strategic Management Journal 32(13): 1500-1516.

Hodgkinson GP, Sadler-Smith E, Burke LA, Claxton G and Sparrow PR (2009) Intuition in organizations: Implications for strategic management. Long Range Planning 42(3): 277-297. Hodgkinson GP, Langan-Fox J and Sadler-Smith E (2008) Intuition: A fundamental bridging construct in the behavioural sciences. British Journal of Psychology 99(1): 1-27.

Hogarth RM (2010) Intuition: A challenge for psychological research on decision making. Psychological Inquiry, 21(4): 338-353.

Huang L and Pearce JL (2015) Managing the unknowable: The effectiveness of early-stage investor gut feel in entrepreneurial investment decisions. Administrative Science Quarterly, DOI: $10.1177 / 0001839215597270$.

Hyppanen, O (2014) Interview data and grounded theory when studying the use of intuition in decision making. In: Sinclair M (ed) Handbook of Research Methods on Intuition. Cheltenham: Edward Elgar, 233-245.

James W (1890/2007) Principles of Psychology, Volume 1. New York: Cosimo Kahneman D (2011) Thinking, fast and slow. London: Allen Lane 
Kahneman D and Klein GA (2009) conditions for intuitive expertise: A failure to disagree. The American Psychologist 64(6): 515-526.

Keller J and Bless H (2008) Predicting future affective states: How ease-of-retrieval and faith in intuition moderate the impact of activated content. European Journal of Social Psychology 38: 1-10.

Keren G (2013) A tale of two systems a scientific advance or a theoretical stone soup? Commentary on Evans \& Stanovich (2013). Perspectives on Psychological Science 8(3): $257-262$.

Khatri N and Ng HA (2000) The role of intuition in strategic decision making. Human Relations 53(1): 57-86.

Kickul J, Gundry LK, Barbosa SD \& Whitcanack L (2009) Intuition versus analysis? Testing differential models of cognitive style on entrepreneurial self-efficacy and the new venture creation process. Entrepreneurship Theory and Practice 33(2): 439-453.

Klein GA (1998) Sources of Power: How people make decisions. Cambridge: MIT Press. Klein GA (2003) Intuition at Work. New York: Currency Doubleday.

Klein GA, Calderwood R and Clinton-Cirocco A (1988) Rapid decision making on the fireground. Alexandria: U.S. Army Research Institute for the Behavioural and Social Sciences. Kruglanski AW (2013) Only one? The default interventionist perspective as a unimodelCommentary on Evans \& Stanovich (2013) Perspectives on Psychological Science 8(3): 242-247.

Lakoff G and Johnson M (1980) Metaphors We Live By. Chicago: University of Chicago Press.

Lakoff G and Johnson M (1999) Philosophy in the Flesh: The Embodied Mind and its Challenge to Western Thought. New York: Basic Books. 
Landis JR and Koch GG (1977) The measurement of observer agreement for categorical data. Biometrics, 33(1): 159-174.

Langley A and Abdallah C (2011) Templates and turns in qualitative studies of strategy and management. Research Methodology in Strategy and Management 6: 201-235.

Li PP (2014) Toward the geocentric framework of intuition: the Yin-Yang balancing between the eastern and Western perspectives on intuition. In: Sinclair M (ed.) Handbook of Research Methods on Intuition. Cheltenham: Edward Elgar, 28-41.

Lieberman MD (2007) Social cognitive neuroscience: A review of core processes. Annual Review of Psychology 58: 259-289.

Lieberman MD, Jarcho JM and Satpute AB (2004) Evidence-based and intuition-based selfknowledge: An fMRI study. Journal of Personality and Social Psychology 87: 421-435.

Merleau-Ponty M (1945/1996) The Phenomenology of Perception (translated from the French by Colin Smith). London: Routledge.

Miles A and Sadler-Smith E (2014). "With recruitment I always feel I need to listen to my gut": The role of intuition in employee selection. Personnel Review 43(4): 606-627. Miller CC and Ireland RD (2005) Intuition in strategic decision making: Friend or foe in the fast-paced 21st century? Academy of Management Executive 19(1): 19-30.

Miller AI (1992) Imagery and intuition in creative scientific thinking: Albert Einstein's invention of the special theory of relativity. In: Wallace DB and Gruber HE (eds) Creative People at Work: Twelve Cognitive Case Studies. Oxford: Oxford University Press, 171-187 Mitchell JR, Friga PN and Mitchell RK (2005) Untangling the intuition mess: Intuition as a construct in entrepreneurship research. Entrepreneurship Theory and Practice 29(6): 653679.

Morgan G (1980) Paradigms, metaphors, and puzzle solving in organization theory. Administrative Science Quarterly 25(4): 605-622. 
Nag R, Corley KG and Gioia DA (2007) The intersection of organizational identity, knowledge, and practice: Attempting strategic change via knowledge grafting. Academy of Management Journal 50(4): 821-847.

Osman M (2004) An evaluation of dual-process theories of reasoning. Psychonomic Bulletin \& Review 11(6): 988-1010.

Panksepp J (2003) At the interface of the affective, behavioural, and cognitive neurosciences: Decoding the emotional feelings of the brain. Brain and Cognition 52(1): 4-14.

Parikh J, Neubauer F and Lank AG (1994) Intuition: The New Frontier of Management, London: Blackwell.

Payne TE (1997) Describing Morphosyntax: A guide for Field Linguists. Cambridge: Cambridge University Press.

Pennebaker JW, Mehl MR and Niederhoffer KG (2003). Psychological aspects of natural language use: Our words, our selves. Annual Review of Psychology 54(1): 547-577.

Petitmengin C (1999) The intuitive experience. In: Varela FJ and Shear J (eds) The View from Within. First-person Approaches to the Study of Consciousness. London: Imprint Academic, 43-77.

Petitmengin C (2006) Describing one's subjective experience in the second person: An interview method for the science of consciousness. Phenomenology and the Cognitive Sciences 5(3-4): 229-269.

Petitmengin C (2014) Researching the micro-dynamics of intuitive experience. In: Sinclair M (ed.) Handbook of Research Methods on Intuition. Cheltenham: Edward Elgar, 188-198 Pinker S (2014) The Sense of Style: The Thinking Persons' Guide to Writing in the $21^{\text {st }}$ Century. London: Allen Lane. 
Pratt MG, Rockmann KW and Kaufmann J.B (2006) Constructing professional identity: The role of work and identity learning cycles in the customization of identity among medical residents. Academy of Management Journal 49(2): 235-262.

Sadler-Smith E (2015) The role of intuition in entrepreneurship and business venturing decisions. European Journal of Work and Organizational Psychology (DOI: $10.1080 / 1359432 X .2015 .1029046)$

Sadler-Smith E and Burke-Smalley LA (2015) How much do we really understand about how managers make important decisions? Organizational Dynamics 44(1): 9-16.

Sadler-Smith E and Shefy E (2004) The intuitive executive: Understanding and applying 'gut feel' in decision-making. Academy of Management Executive 18(4): 76-91.

Sadler-Smith E and Shefy E (2007) Developing intuitive awareness in management education. Academy of Management Learning \& Education 6(2): 186-205.

Salas E, Rosen MA and DiazGranados D (2010) Expertise-based intuition and decision making in organizations. Journal of Management 36(4): 941-973.

Segalowitz SJ (2007) Knowing before we know: Conscious versus preconscious top-down processing and a neuroscience of intuition. Brain and Cognition 65(2): 143-144.

Simon HA (1987) Making management decisions: The role of intuition and emotion. The Academy of Management Executive 1(1): 57-64.

Sinclair M (2010) Misconceptions about intuition. Psychological Inquiry 21(4): 378-386.

Sinclair M (2011) Introduction. In: Sinclair M (ed) Handbook of Intuition Research. Cheltenham: Edward Elgar, xvi-xviii.

Sinclair M (2014) Introduction. In: Sinclair M (ed) Handbook of Research Methods on Intuition. Cheltenham: Edward Elgar, xvii-xix.

Sinclair M and Ashkanasy NM (2005) Intuition myth or a decision-making tool? Management Learning 36(3): 353-370. 
Sinclair M, Ashkanasy NM, Chattopadhyay P and Boyle MV. (2002). Determinants of intuitive decision making in management: The moderating role of affect. In: Ashkanasy NM, Zerbe WJ and Hartel CEJ (eds.) Managing Emotions in the Workplace. New York; ME. Sharpe Inc., 143-163.

Slovic P, Finucane ML, Peters E and MacGregor DG (2004) Risk as analysis and risk as feelings: Some thoughts about affect, reason, risk, and rationality. Risk Analysis 24(2): 311322.

Stanovich KE and West RF (2000) Individual differences in reasoning: Implications for the rationality debate? Behavioural and Brain Sciences 23(5): 645-665.

Stanovich KE (2009) What Intelligence Tests Miss: The Psychology of Rational Thought. New Haven: Yale University Press.

Sternberg RJ and Davidson JE (1995) The Nature of Insight. Cambridge: The MIT Press. Teerikangas S and Välikangas, L (2014) Exploring the dynamic of evoking intuition. In: Sinclair M (ed) Handbook of Research Methods on Intuition. Cheltenham: Edward Elgar, $72-87$.

Tomasino DE (2011) The heart in intuition: tools for cultivating intuitive intelligence. In: Sinclair M (ed.) Handbook of intuition research. Cheltenham: Edward Elgar, 247-260. Tosey P and Mathison J (2010) Exploring inner landscapes through psycho-phenomenology: The contribution of neuro-linguistic programming to innovations in researching first person experience. Qualitative Research in Organizations and Management: An International Journal, 5(1): 63-82.

Tsoukas H (1991) The missing link: A transformational view of metaphors in organizational science. Academy of Management Review 16(3): 566-585.

Varela FJ and Shear J (1999) The View From Within. First-Person Approaches to the Study of Consciousness. London: Imprint Academic. 
Vaughan FE (1979) Awakening Intuition. New York: Doubleday.

Wallas, G (1926) The Art of Thought. London: Jonathan Cape.

Willman P, Fenton-O’Creevy M, Nicholson MN and Soane E (2001) Knowing the risk:

Theory and practice in financial market trading. Human Relations 54(7): 11-25. 
Figure 1. Data structure (dimensions [bold], themes [italic], first-order concepts [normal text], and sample units of text [numerals in brackets indicate which participant is being quoted])

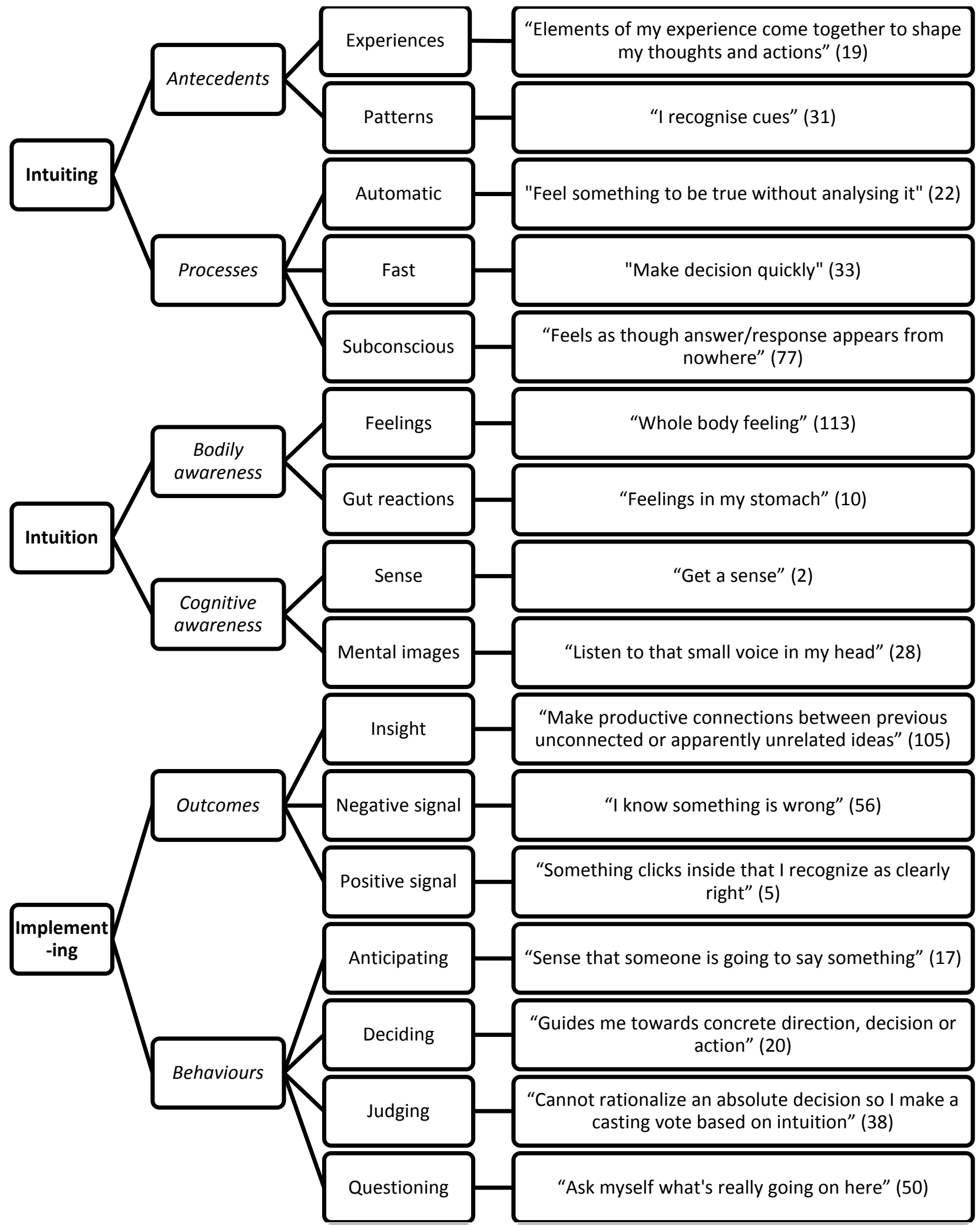


Figure 2a. 'Intuiting-intuitive judgement' model (see Dane \& Pratt, 2007)

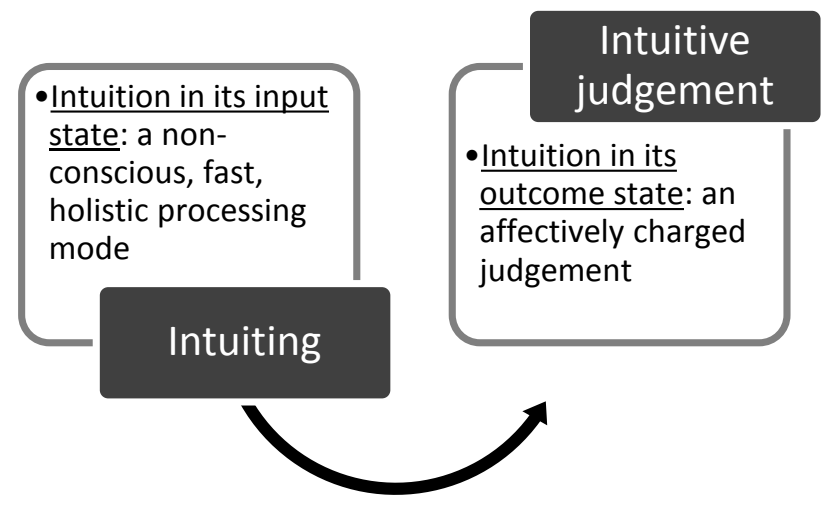

Figure 2b. 'Intuiting-intuition-implementing' model

- Automatic, rapid, subconscious processing; response to recognized patterns, supported/enabled by informational substrates from past experiences/prior learnings

\section{Intuiting}

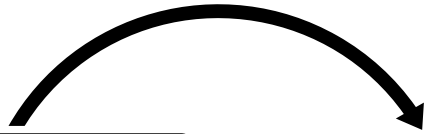

- Intuitions provide subjective evaluations and insights that may be used to guide subsequent behaviours in decision making, problem solving, and creativity.

'

'feeling' states; (2) cognitive awareness: general 'sense' and mental images (visual, auditory)

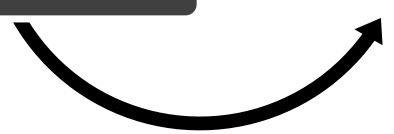


Figure 3. Typology of intuitive affect

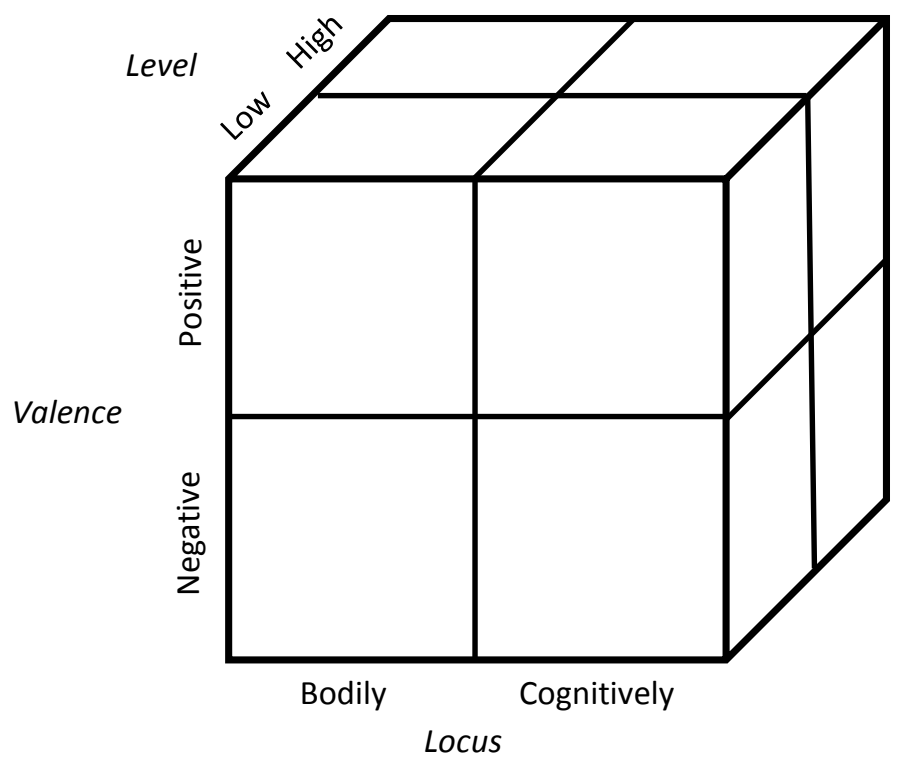


Appendix 1. Numbers of units of text by first-order concepts, themes and dimensions

\begin{tabular}{|c|c|c|c|c|c|c|c|}
\hline \multirow[b]{2}{*}{$1^{\text {st }}$ order concepts } & \multicolumn{2}{|c|}{ Intuiting } & \multicolumn{2}{|c|}{ Intuition } & \multicolumn{2}{|c|}{ Implementing } & \multirow[b]{2}{*}{ Totals } \\
\hline & Antecedents & Processes & Bodily awareness & Cognitive awareness & Outcomes & Behaviours & \\
\hline Experience & 14 & & & & & & 14 \\
\hline Patterns & 7 & & & & & & 7 \\
\hline Automatic & & 27 & & & & & 27 \\
\hline Fast & & 8 & & & & & 8 \\
\hline Subconscious & & 7 & & & & & 7 \\
\hline Gut reactions & & & 23 & & & & 23 \\
\hline Feelings & & & 20 & & & & 20 \\
\hline Sense & & & & 7 & & & 7 \\
\hline Mental images & & & & 5 & & & 5 \\
\hline Insight & & & & & 10 & & 10 \\
\hline Negative signal & & & & & 12 & & 12 \\
\hline Positive signal & & & & & 26 & & 26 \\
\hline Anticipating & & & & & & 8 & 8 \\
\hline Deciding & & & & & & 14 & 14 \\
\hline Judging & & & & & & 19 & 19 \\
\hline Questioning & & & & & & 5 & 5 \\
\hline Totals & 21 & 42 & 43 & 12 & 48 & 46 & 212 \\
\hline
\end{tabular}




\section{Acknowledgements}

I am grateful to colleagues Dr. Jane Mathison and Dr. Paul Tosey for inspiration and advice on (de-)nominalization and psycho-phenomenology.

\section{Author Biography}

Eugene Sadler-Smith is Professor of Organizational Behaviour, Surrey Business School, University of Surrey, UK. His current research interests are: intuition in organizational decision making; insight in invention and innovation; and hubris and virtue ethics in management and leadership. He is the author of a number of research articles on intuition and these have published in journals such as Academy of Management Executive, Academy of Management Learning \& Education, British Journal of Psychology, Organization Studies, etc., also he has written two books on the subject Inside Intuition (2008, Routledge) and The Intuitive Mind (2010, John Wiley and Sons). His intuition research has had wider coverage in the practitioner press (for example, People Management) as well as on BBC Radio 4 and in The Times newspaper. [Email: e.sadler-smith@surrey.ac.uk]

\section{Corresponding Author}

Eugene Sadler-Smith

Professor of Organizational Behaviour

Surrey Business School

University of Surrey

Guildford, GU2 7XH

UNITED KINGDOM

Tel: 01483683101

e.sadler-smith@surrey.ac.uk 